\title{
Quantitative Analysis of Forthcoming ICC Men's T20 World Cup 2020 Winner Prediction using Machine Learning
}

\author{
Shashank Singh \\ B. Tech Student \\ Department of CSE \\ Inderprastha Engineering \\ College, Ghaziabad, India
}

\author{
Yash Aggarwal \\ B. Tech Student \\ Department of CSE \\ Inderprastha Engineering \\ College, Ghaziabad, India
}

\author{
Kumud Kundu, PhD \\ Assistant Professor \\ Department of CSE \\ Inderprastha Engineering College, \\ Ghaziabad, India
}

\begin{abstract}
The ICC Men's T20 Cricket World Cup 2020 is scheduled to be hosted by Australia in the month of October and November 2020. Machine Learning in sports analytics is now a days actively applied for prediction of winners. The work presented in this paper aims to predict the winner of the upcoming seventh version of ICC Men's T20 world cup using Random Forest Classifier, Naïve Bayes, KNN, Logistic Regression, Decision Tree, SVM, Bagging Classifier, Extra Trees Classifier, Voting (HARD \& SOFT) training. All these approaches are tested on the different available historic data of international cricket matches played between different countries from 2005 to March 2020. Unstructured historic cricket statistics is picked from ESPN and Cricbuzz websites. Experimental results prove that all approaches are able to imbibe the extracted patterns from the various set of matches performed and hence is found suitable to predict the winner of the ICC Men's T20 Cricket World Cup 2020. A comparative study is also presented for the predictions made through different approaches.
\end{abstract}

\section{General Terms}

Machine Learning, Match Outcome.

\section{Keywords}

Cricket analytics, Winner Prediction, Classification.

\section{INTRODUCTION}

In India, Cricket is one of the most popular sport that has huge fan base. This sport is played at the national as well as international level. At international level, Indian national team plays different bilateral matches with the national team of other countries as well as it plays in the World Cup tournaments. Cricket's World Cup tournaments are organized by governing body: International Cricket Council (ICC). Cricket world tournaments are open to all its council members. The highest-ranking teams as per the ICC ranking list qualify to the world cup tournaments automatically. However, the remaining teams are picked through the ICC world cup qualifier matches. Cricket world cup tournaments is currently being held in two formats: T20 world cup tournament and ODI cricket world cup tournament. First format of cricket international championship is held every two years and another one is held every four years. The ICC Men's T20 World Cup (earlier known as ICC World Twenty20) is the international championship played by the sixteen teams. Out of sixteen teams, ten teams qualify directly into the tournament on the basis of the ranking furnished by the ICC while the other six other teams are chosen through the T20
World Cup Qualifier. The next edition of T20 world cup tournament is planned to be held in Australia from 18 October to 15 November 2020. As per the ICC ranking of 31 December 2018, the top nine ranked teams, along with host country Australia, had qualified directly for the 2020 tournament. Out of those ten qualifier teams, the top eight ranked teams had qualified for the Super 12 stage of the tournament while the teams of Sri Lanka and Bangladesh were placed in the group stage of the competition. Six other teams who had qualified for the tournament through the ICC T20 World Cup Qualifiers also include the United Arab Emirates and Nepal.

Recently, machine learning has been applied abundantly for analyzing the sport outcomes based on the data gathered from the past played games. The learning process involves training the model based on previous matches played, then the developed model gets evaluated on an independent future match to measure its effectiveness [1]. However, doing analysis and predictions from the huge volume of unstructured data generated from the matches played during a tournament poses a big challenge in itself. This paper presents the methodology of predicting the winner of the upcoming men's T20 Cricket World Cup 2020 using machine learning. The prediction accuracies of various machine learning algorithms are compared to study their performance.

The paper is organized as follows. Section 2 provides a brief literature survey of the approaches used in cricket analytics. Section 3 describes our methodology for predicting the winner of the tournament. In Section 4 results are presented while Section 5 presents the conclusion of the paper and puts forth the further direction of work that can be done to improve results further.

\section{LITERATURE SURVEY}

Since past two decades, Machine Learning has become one of the active ingredients in improving the performance of computer system. In the field of sports, Machine learning has paved its path in the prediction of performance of team as well as team members. Pathak et al. [2] developed COP (Cricket Outcome Predictor) where they applied Naïve Bayesian classifier for the prediction of the probability of win/loss of an ODI match. Passi et al. [3] applied four machine learning algorithms: Naïve Bayes, Decision Trees, Random Forest and Support Vector Machine for predicting the runs scored by a batsman and wickets taken by a bowler in ODI match. They found among the four machine learning algorithms that they considered, Random Forest turns out to be the most accurate classifier for the prediction of the runs 
scored by a batsman and the prediction for predicting wickets taken by a bowler. Jayalath [4] studied the effect of predictors like: home-field advantage, coin toss result, bat-first or second, day vs day-night game etc that affect the prediction of ODI outcome using 'classification and regression tree' CART-based approach. They found that the home-field advantage factor impacts the winning probability significantly for various teams like India, South Africa, Sri Lanka, New Zealand, and Pakistan. It was further found that for the South African team, home ground factor affects the winning probability more than the other teams. Viswanadha et al. [5] modelled the parameters affecting relative strength of the two teams playing the T20 match. In their work, they estimated the team's strength by modeling the potential of the individual participating players by utilizing player's recent performance statistics. The modelled features were evaluated using several supervised learning algorithms for the prediction of the T20 match winner. Rupai et al. [6] studied the impact of bowling performance on the match winning probability. They utilized various machine learning based approaches to predict the bowler's performance in various instances of ODI matches. Wickramasinghe [7] utilized three machine learning classifiers, namely Naive Bayes (NB), k-nearest neighbours $(\mathrm{kNN})$, and Random Forest (RF) for the classification of allround player's performance in ODI matches. Modekurti et al. [8] developed a deterministic model for the determination of the target score of the team batting first in T-20 Indian Premier League (IPL) match.

\section{PROBLEM FORMULATION \& PROPOSED SOLUTION}

To study the classification accuracy of popular machine learning algorithms for the prediction of winner of upcoming ICC T20 Men's world cup. Outcome of each machine learning algorithm deals with the hypothesis question: " $H=C o m p u t e d$ feature score is probable to put forth as a future ICC T20 tournament winner or not?".

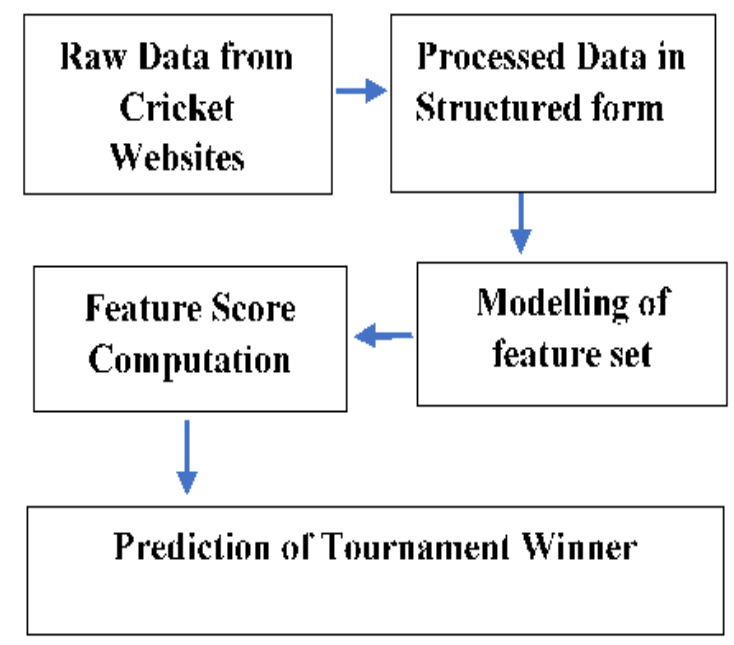

Fig 1: Proposed Solution

Hypothesis testing incorporates six phases i.e. data acquisition, data validation (if required), feature modelling, extraction of correlations among the modelled feature set, design of: train data set, test data set, validation data set, data model execution with selected machine learning algorithm. With regards to research, the data is known to be validated as both data sources are trustworthy. there is no invalid data to remove. The dataset acquired from
ESPNcricinfo [9] can be classified as enterprise datasets as the data structure is predefined and the dataset is prevalidated.

\subsection{Datasets}

This paper is adopting datasets from different online available resources ESPNcricinfo, Cricbuzz. Most of the datasets that it will be using would be of the structured type, as the cricket statistics are data that conform to a data model and is often not stored in tabular form. Following datasets are used to derive experimental results:

\subsubsection{T20 Stats Dataset}

Table 1 below shows an example of the results of a statistics query team in T20s for the past 15 years (2005 to present time) from ESPNcricinfo [10]. The dataset T20 stat shows the data of every single T20 match played from 2005 to 2020 and contains a total of 1070 records. This table stores useful information such as the two teams, the winner, and the margin of the win, the venue, and the date.

Table 1. Historical T20 matches

\begin{tabular}{|c|c|c|c|c|c|}
\hline Date & Team_1 & Team_2 & Winner & Margin & Ground \\
\hline $\begin{array}{c}\text { Feb 17, } \\
2005\end{array}$ & $\begin{array}{c}\text { New } \\
\text { Zealand }\end{array}$ & Australia & Australia & 44 runs & Auckland \\
\hline $\begin{array}{c}\text { Jun } 13, \\
2005\end{array}$ & England & Australia & England & 100 runs & $\begin{array}{c}\text { Southampt } \\
\text { on }\end{array}$ \\
\hline $\begin{array}{c}\text { Oct } 21 \text {, } \\
2005\end{array}$ & $\begin{array}{l}\text { South } \\
\text { Africa }\end{array}$ & $\begin{array}{c}\text { New } \\
\text { Zealand }\end{array}$ & $\begin{array}{c}\text { New } \\
\text { Zealand }\end{array}$ & 5 wickets & $\begin{array}{c}\text { Johannesb } \\
\text { urg } \\
\end{array}$ \\
\hline $\begin{array}{c}\text { Jan 9, } \\
2006 \\
\end{array}$ & Australia & $\begin{array}{l}\text { South } \\
\text { Africa }\end{array}$ & Australia & 95 runs & Brisbane \\
\hline $\begin{array}{c}\text { Feb 16, } \\
2006\end{array}$ & $\begin{array}{c}\text { New } \\
\text { Zealand }\end{array}$ & $\begin{array}{l}\text { West } \\
\text { Indies } \\
\end{array}$ & tied & $\mathrm{NaN}$ & Auckland \\
\hline$\ldots$ & $\ldots$ & $\ldots$ & $\ldots$ & $\ldots$ & $\ldots$ \\
\hline $\begin{array}{c}\text { Feb 26, } \\
2020\end{array}$ & $\begin{array}{l}\text { South } \\
\text { Africa }\end{array}$ & Australia & Australia & 97 runs & Cape Town \\
\hline $\begin{array}{c}\text { Feb 27, } \\
2020\end{array}$ & Kuwait & U.A.E. & U.A.E. & 102 runs & Al Amerat \\
\hline $\begin{array}{c}\text { Feb 29, } \\
2020\end{array}$ & Thailand & Singapore & Singapore & 43 runs & Bangkok \\
\hline
\end{tabular}

\subsubsection{T20 Fixtures Dataset}

Detailed fixtures of the T20 World Cup are stored in T20 Fixtures dataset. This dataset stores information like date, venue, team name, group, round. T20 fixtures dataset is derived from the Cricbuzz website [11] which has the detailed list of fixtures of upcoming T20 world cup. The fixture data available at Cricbuzz website was in raw format, that's why the data was converted into the structured format. Table 2 shows an example of this. It presents every fixture record with attributes like date, team name.

Table 2. Fixtures of the Forthcoming T20 World Cup 2020

\begin{tabular}{|c|c|c|c|c|}
\hline Date & Location & Team_1 & Team_2 & Group \\
\hline 18-Oct-20 & Simonds Stadium & Sri Lanka & Ireland & Group A \\
\hline 18-Oct-20 & \multicolumn{2}{|c|}{ Simonds Stadium Papua New Guinea } & Oman & Group A \\
\hline 19-Oct-20 & Bellerive Oval & Bangladesh & Namibia & Group B \\
\hline 19-Oct-20 & ve Oval & Neth & $\mathrm{Scc}$ & Group B \\
\hline 20-Oct-20 & Simor & & On & $\mathrm{Gr}$ \\
\hline $20-O c t-20$ & Simon & & Papua New Guinea & \\
\hline 21-Oct-20 & Bellerive Oval & jia & Scotland & Group B \\
\hline 21-Oct-20 & Bellerive Oval & Bangladesh & Netherlands & Group B \\
\hline 22-Oct-20 & Simonds Stadium & pua New Guinea & Ireland & Group A \\
\hline
\end{tabular}




\subsubsection{ICC Ranking Dataset}

All 16 teams participating in the upcoming world cup in 2020 have their respective rankings allotted by the ICC [12]. ICC Team Rankings is computed from the score points scored by a team on the basis of the results of the matches played by a team over the last 3-4 years. For instance, the ICC rankings of 16 teams is shown in Table 3 .

Table 3. ICC Rankings and Points [12]

\begin{tabular}{|c|c|c|}
\hline Position & Team & Points \\
\hline 1 & Australia & 278 \\
\hline 2 & England & 268 \\
\hline 3 & India & 266 \\
\hline 4 & Pakistan & 260 \\
\hline 5 & South Africa & 258 \\
\hline 6 & New Zealand & 242 \\
\hline 7 & Sri Lanka & 230 \\
\hline 8 & Bangladesh & 229 \\
\hline 9 & West Indies & 229 \\
\hline 10 & Afghanistan & 228 \\
\hline 12 & Ireland & 190 \\
\hline
\end{tabular}

\subsubsection{Master Dataset}

Apart from the standard datasets, another dataset is designed as a master data set based on T20 stats dataset and ICC rankings dataset. This data set stores the computed feature score from the modelled feature set for every team. This particular dataset is built in order to summarize every vital feature of a cricket team like number of T20 matches played till date, winning percentage in those matches, no. of matches played in Australia, etc. Table 4 shows the feature score of every team while prioritizing every variable according to its importance. Features in the Mater Dataset are:

- $\quad$ ICC Ranking Rating (T20)

- Overall Matches Played (T20)

- Overall Winning Percentage (T20)

- $\quad$ Mean Batting Average

- Average Bowling Economy

- $\quad$ Matches Played in Australia (T20)

- Winning Percentage in Australia (T20)

- $\quad$ Matches Played after ICC World Cup 2019

- Winning Percentage after ICC World cup 2019

Table 4. Master Dataset

\begin{tabular}{|c|c|c|c|c|c|c|c|}
\hline Team & IRR & OMP & OWP & MB A & ABE & MPA & WPA \\
\hline Australia & 278 & 125 & 55.73 & 25 & 2.64 & 43 & 62.79 \\
\hline England & 268 & 117 & 52.21 & 30 & 1.74 & 8 & 12.5 \\
\hline India & 266 & 134 & 65 & 33 & 2.84 & 9 & 55.55 \\
\hline Pakistan & 260 & 151 & 62.33 & 29 & 3.12 & 4 & 0 \\
\hline South Africa & 258 & 121 & 58.75 & 25 & 1.79 & 7 & 28.57 \\
\hline New Zealand & 242 & 131 & 50.78 & 24 & 1.8 & 3 & 0 \\
\hline Sri Lanka & 230 & 128 & 47.61 & 15 & 2.24 & 9 & 55.55 \\
\hline Bangladesh & 229 & 96 & 34.04 & 23 & 1.91 & 0 & 0 \\
\hline West Indies & 229 & 124 & 46.63 & 20 & 1.77 & 3 & 33.34 \\
\hline Afghanistan & 228 & 81 & 68.71 & 25 & 3.06 & 0 & 0 \\
\hline Ireland & 190 & 98 & 46.15 & 28 & 2.56 & 0 & 0 \\
\hline Scotland & 182 & 65 & 47.58 & 29 & 2.14 & 0 & 0 \\
\hline Papua New & 179 & 26 & 68 & 23 & 4.47 & 0 & 0 \\
\hline Guinea & 178 & 75 & 54.86 & 25 & 2.81 & 0 & 0 \\
\hline Netherlands & & & & & & & \\
\hline
\end{tabular}

\subsection{Modelling of Feature Set}

- ICC Ranking Rating (IRR): This particular feature shows the current ICC T20 Team ranking of all the teams participating the T20 World Cup 2020.

- Overall Matches played (OMP): It shows the total matches played till date from 2005 till 2020.

- Overall Winning Percentage (OWP): This feature is calculated by dividing the Overall Matches Played by the Overall matches won (OMW) by the team i.e.

$\mathrm{OWP}=\mathrm{OMP} / \mathrm{OMW}$

- Mean Batting Average (MBA): It shows the average no. of runs a batsman score. This average is calculated on the basis of maximum runs scored by the best 3 batsmen of a team for last 2 years.

- Average Bowling Economy (10 - BE): It shows the average number of runs a bowler concedes in an over. This feature is also calculated by the max. no of runs by the best 3 bowlers for the last 2 years.

- Matches played in Australia (MPA): It shows the number of T20 matches played by the particular team in Australia.

- Winning percentage in Australia (WPA): This feature is calculated by dividing the MPA by the number of matches won by the team in Australia (MWA). This feature is used since the T20 World Cup 2020 will be played in Australia i.e.

WPA $=$ MPA/MWA .........

- $\quad$ Matches played after 2019 World Cup (MPN): It shows the number of matches played by any team after the 2019 World Cup. This particular feature is used to analyze the team performance and confidence during this time.

- Winning Percentage after 2019 World Cup (WPN): This feature is calculated by dividing MPN by the matches won after 2019 World Cup (MWN).

$\mathrm{WPN}=\mathrm{MPN} / \mathrm{MWN}$

- The final feature score is computed by the following formula:

Feature Score $(F S)=$ ICC ranking*a + OMP*b + OWP*c $+M B A * d+A B E * e+M P A * f+W P A * g+M P N * h+$ WPN*i

Where a, b, c, d, e, f, g, h, i are empirical variables whose values are experimentally taken as: $\mathrm{a}=0.25, \mathrm{~b}=1.5, \mathrm{c}=1.5$, $\mathrm{d}=1.25, \mathrm{e}=1.25, \mathrm{f}=1.5, \mathrm{~g}=1.5, \mathrm{~h}=1.25, \mathrm{i}=1.25$. These empirical variables are used to prioritize the individual features described above in the calculation of the final feature score.

\subsection{PREDICTION ALGORITHM}

To predict the winner of tournament ICC Men's T20, popular machine learning classifier like: Random Forest, Naïve Bayes, KNN, Logistic Regression, Decision Tree, SVM, Bagging Classifier, Extra Trees Classifier [13] have been applied. Following tasks are performed on datasets before applying prediction algorithm:

\section{- $\quad$ Importing the required Python Libraries}

- Importing and reading the T20 Stat Dataset containing information about the historical T20 matches 
played till date.

- Importing and reading the T20 Fixture Dataset having the fixtures for the upcoming ICC T20 World Cup 2020.

- Narrowing down the T20 Stat Dataset to those teams which will be playing the World cup.

- Dropping attributes or columns like Ground and Margin that will not affect match outcomes.

Table 5. Dataset with Dropped Attributes

\begin{tabular}{|c|c|c|c|}
\hline S.No & Team_1 & Team_2 & Winner \\
\hline 1 & $\begin{array}{c}\text { New } \\
\text { Zealand }\end{array}$ & Australia & Australia \\
\hline 2 & England & Australia & England \\
\hline 3 & Australia & South Africa & Australia \\
\hline 4 & $\begin{array}{c}\text { New } \\
\text { Zealand }\end{array}$ & West Indies & tied \\
\hline 5 & England & Sri Lanka & Sri Lanka \\
\hline$\ldots$ & $\ldots$ & $\ldots$ & $\ldots$ \\
\hline 1060 & South Africa & England & South Africa \\
\hline 1061 & South Africa & England & England \\
\hline 1062 & South Africa & England & England \\
\hline
\end{tabular}

\section{EXPERIMENTAL RESULTS}

This section presents the experimental results with the abovementioned datasets and the prediction algorithms.

\subsection{Prediction on the basis of Feature Score Ranking}

Table 6 below shows the Prediction Set where the 'team feature score' is embedded with its name

Table 6: Prediction of Round 1 on the Basis of Feature Score

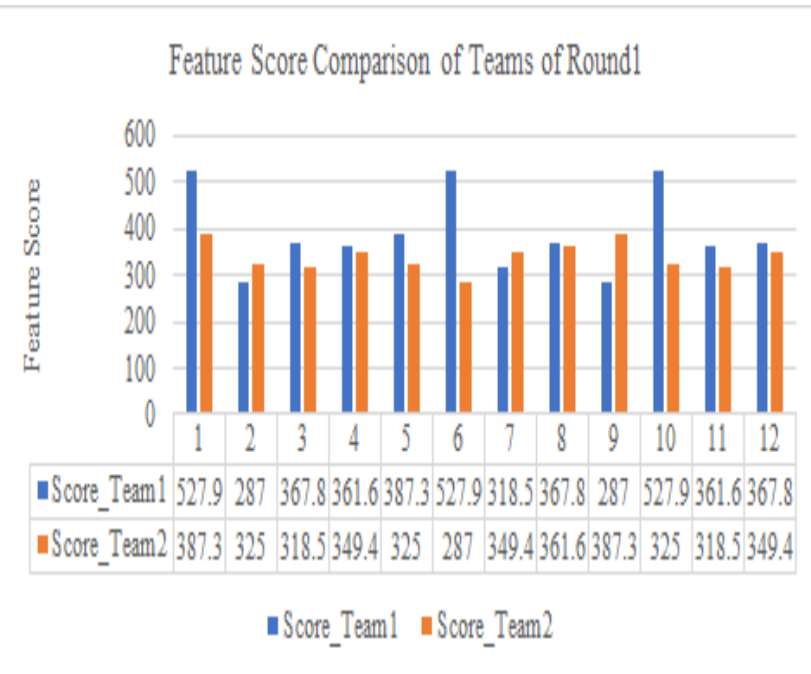

\begin{tabular}{|l|l|l|}
\hline Team_1 & Team_2 & Predicted Winner \\
\hline SriLanka & Ireland & SriLanka \\
\hline Papua New Guinea & Oman & Oman \\
\hline Bangladesh & Namibia & Bangladesh \\
\hline Netherlands & Scotland & Netherland \\
\hline Ireland & Oman & Ireland \\
\hline & & \\
\hline SriLanka & Papua New Guinea & Srilanka \\
\hline Namibia & Scotand & Scotland \\
\hline Bangladesh & Netherlands & Bangladesh \\
\hline & & \\
Papua New Guinea & Ireland & Ireland \\
\hline SriLanka & Oman & Srilanka \\
\hline Netherlands & Namibia & Netherland \\
\hline Bangladesh & Scotland & Bangladesh \\
\hline
\end{tabular}

\subsection{Match Outcome Prediction}

Figure 2 below shows the snippet of the Prediction of the Group Matches of the ICC T20 World Cup 2020 on the basis of their respective Feature Score.

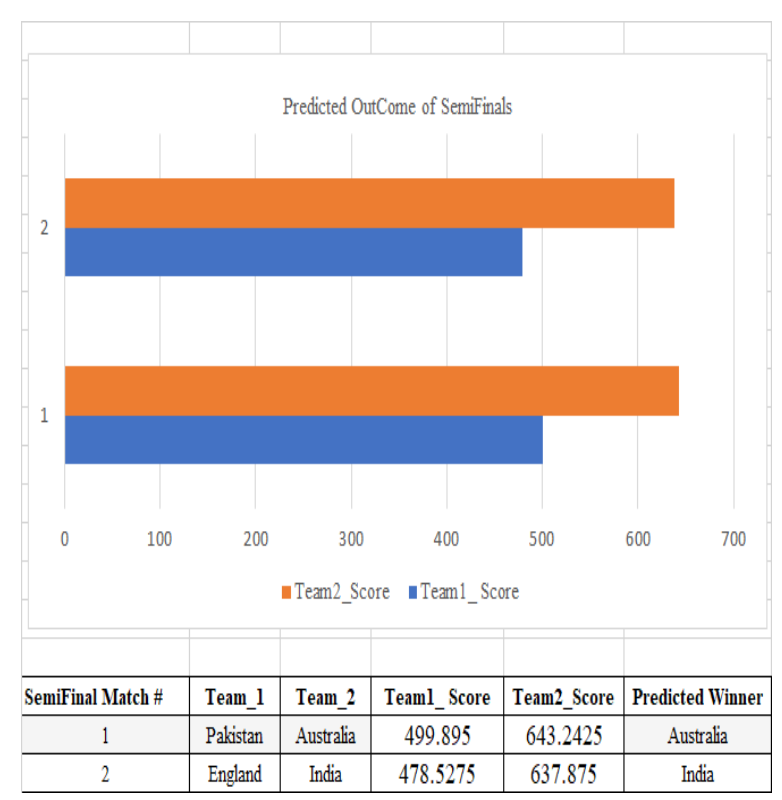

Fig 2: Predicted Winner of Semi Finals

\subsection{Feature Score Comparison}

Figure 3 below shows the comparison of all the teams participating in the T20 World Cup 2020. As shown below Australia and India have the best and the $2^{\text {nd }}$ best feature score respectively. 


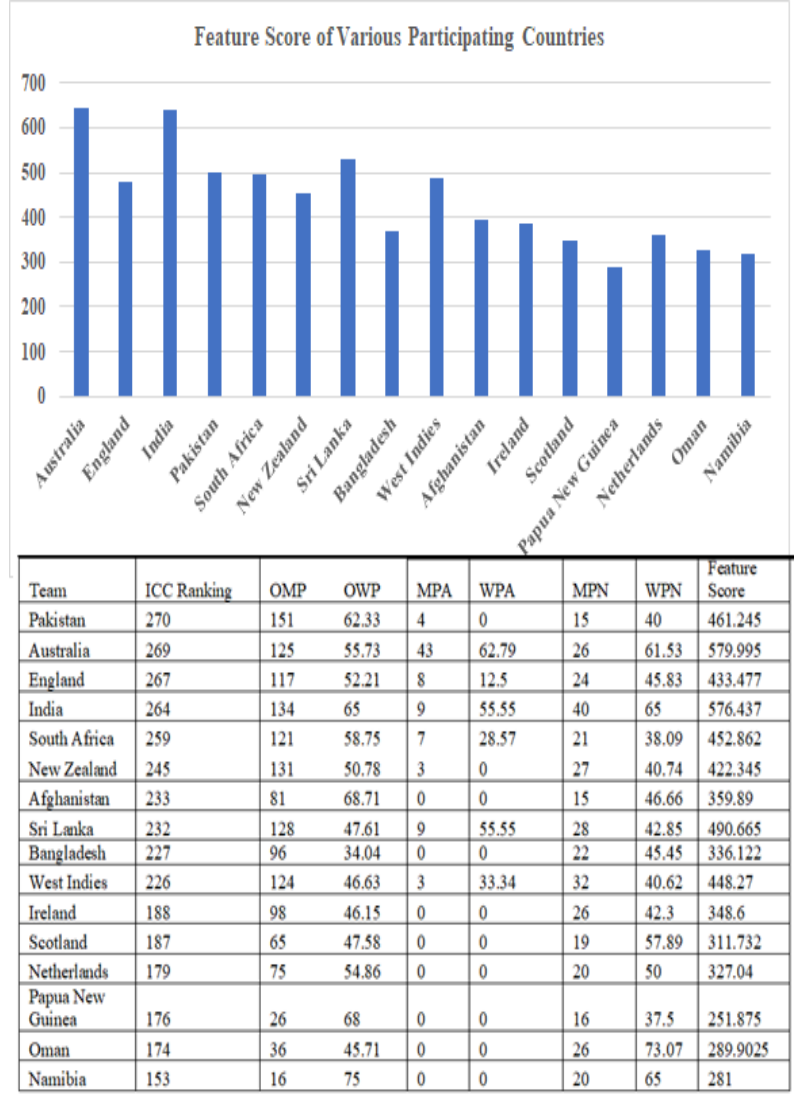

Fig 3: Feature Score Comparison of Top 16 Teams

\subsection{Prediction Comparison}

Figure 4, 5, and 6 below show the prediction comparison results of top three instances with the modelled feature set. In every instance Random Feature algorithm is able to give more score and hence a better picture of prediction outcome.

\section{AUSTRALIA}

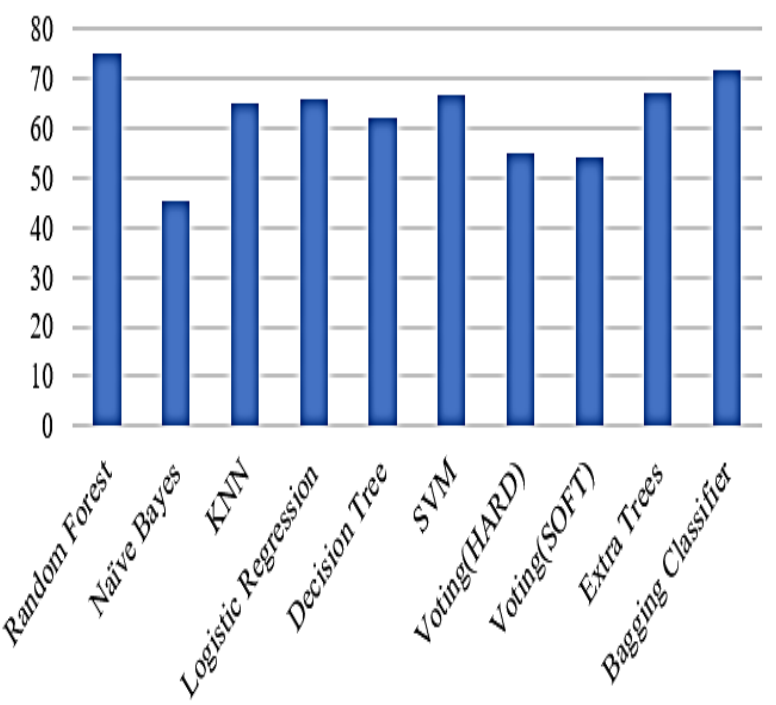

-Prediction Outcome (\%)

Fig 4: Accuracy Comparison of Prediction Algorithms for Australia
INDIA

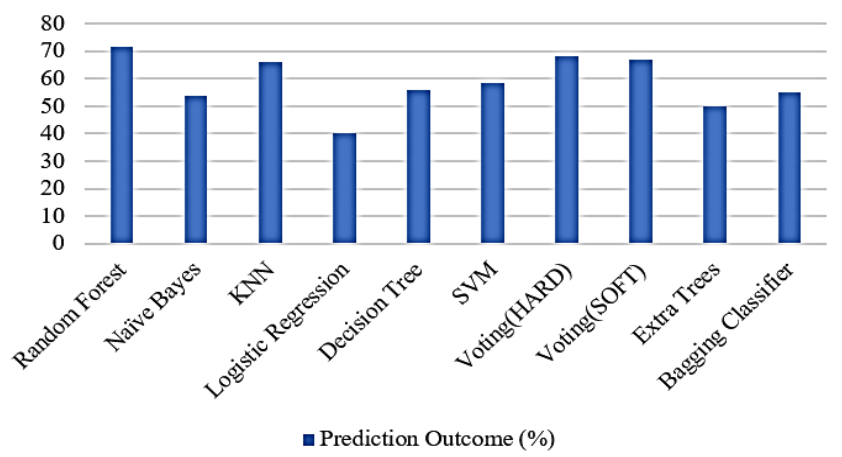

Fig 5: Accuracy Comparison of Prediction Algorithms for India

ENGLAND

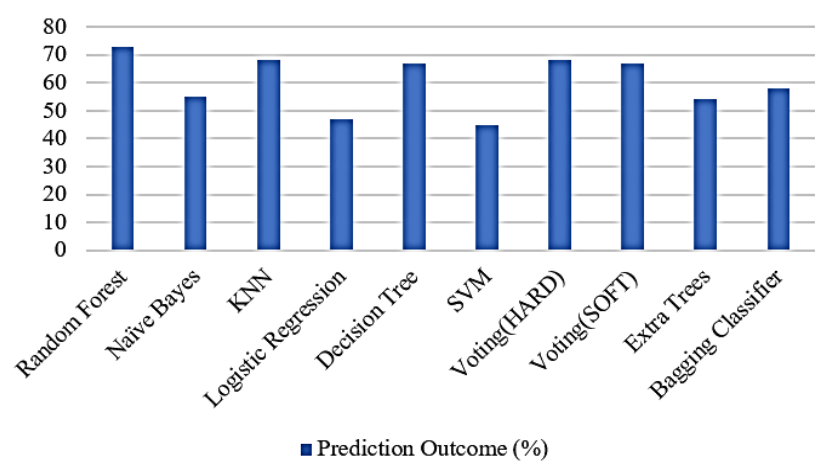

Fig 6: Accuracy Comparison of Prediction Algorithms for England

\subsection{T20 World Cup Winner Prediction}

A system has been created using machine learning in which team with higher Feature Score and previous T20 World Cup records are provided with higher priority in winning a particular match. The team with the higher Feature Score and previous record is predicted to win the world cup. As a result, prediction indicates that Australia has the highest chances to win the world cup and India being in the next possibility being with the $2^{\text {nd }}$ highest Feature score. India trails by a difference of 5.3675 behind Australia in feature score.

\section{CONCLUSION}

This study is an exploratory study aimed to predict the winner of upcoming ICC T20 men's tournament by utilizing few prominent parameters associated with $\mathrm{T} 20$ previous matches. A feature score was computed from the selected parameters to test the formulated hypothesis of predicting probable winner. It is apparent from the accuracy comparison chart that Random Forest algorithm gives the highest prediction as it is able to find the most important feature from the selected feature set and is less prone to overfitting.

\section{REFERENCES}

[1] Munir, F., Hasan, M.K., Ahmed, S., Md Quraish, S., 2015. Predicting a T20 cricket match result while the match is in progress (Doctoral dissertation, BRAC University).

[2] Pathak, N., and Wadhwa, H. 2016. Applications of modern classification techniques to predict the outcome of ODI cricket. Procedia Computer Science, 87, 55-60.

[3] Passi, K., \& Pandey, N. 2018. Increased prediction 
accuracy in the game of cricket using machine learning. arXiv preprint arXiv:1804.04226.

[4] Jayalath, K. P. 2018. A machine learning approach to analyze ODI cricket predictors. Journal of Sports Analytics, 4(1), 73-84.

[5] Viswanadha, S., Sivalenka, K., Jhawar, M. G., \& Pudi, V. 2017. Dynamic Winner Prediction in Twenty 20 Cricket: Based on Relative Team Strengths. In MLSA@ PKDD/ECML, 41-50.

[6] Rupai, A. A. A., Mukta, M. S. H., \& Islam, A. N. 2020. Predicting Bowling Performance in Cricket from Publicly Available Data. In Proceedings of the International Conference on Computing Advancements, $1-6$.

[7] Wickramasinghe, I. Classification of All-Rounders in the
Game of ODI Cricket: Machine Learning Approach.

[8] Modekurti, D. P. V. Setting final target score in T-20 cricket match by the team batting first. Journal of Sports Analytics, (Preprint), 1-8.

[9] ]https://stats.espncricinfo.com/ci/engine/records/index.ht ml?id=89; type $=$ trophy

[10] ]https://www.cricbuzz.com/cricket-series/2798/icc-menst20-world-cup 2020/stats\#!/?statsType $=$ mostRuns\&seriesType $=$ WCT 20 \&seriesId $=2798$.

[11] https://www.cricbuzz.com/cricket-series/2798/icc-menst20-world-cup-2020/matches.

[12] https://www.icccricket.com/rankings/mens/ teamrankings/t20i 